\title{
CASA, CORTE Y CANCILLERÍA DEL OBISPO DE VALENCIA HUG DE LLUPIÀ \\ $(1398-1427)^{1}$
}

\author{
$\mathrm{M}^{\mathrm{a}}$ Milagros CÁRCEL ORTí \\ Universidad de Valencia
}

SUMARIO

1. Introducción.- 2. Casa, corte y cancillería del obispo Hug de Llupià: I. La cancillería. II. La casa y corte. III. Lugares de señorío de la mitra.

\section{INTRODUCCIÓN}

Las letras episcopales son documentos muy poco conocidos en comparación con las reales o las papales, aunque su interés es grande ya que por medio de ellas se gobernó día a día una diócesis, de igual manera que las letras reales son, para la misma época, el medio de gobierno del Estado.

De la estructura de gobierno de la diócesis de Valencia se ha prestado atención a una acción concreta: las visitas pastorales ${ }^{2}$ y se han

\footnotetext{
'Este trabajo se ha beneficiado de la ayuda PS 95-0122 "Escribir la sociedad: Cultura Escrita y memoria hístórica de la Comunidad Valenciana (1238-1474)", concedida por la Dirección General de Enseñanza Superior del Ministerio de Educación y Cultura a la Unidad Docente de Paleografía y Diplomática del Departamento de Historia de la Antigüedad y de la Cultura Escrita de la Universidad de Valencia.

${ }^{2} \mathrm{M}$ a Milagros CáRCEL ORTí y José Vicente BosCà CODina, Visitas pastorales de Valencia (siglos XIV-XV), Valencia, Facultad de Teología San Vicente Ferrer, 1996 (=Series Valentina, XXXVIII).

"Anuario de listudios Medievales". 28 (1998)
} 
publicado también los documentos sinodales ${ }^{3}$. Pero dicho gobierno no se limita a la visita-corrección, sino que comprende un momento legislativo (sínodo), unos actos de inspección general (visita) y una actuación continuada sobre situaciones particulares (decisiones comunicadas por escrito), todo interrelacionado ${ }^{4}$. Estas decisiones que afectan a todo el ámbito del gobierno episcopal (mandatos, citaciones, nombramientos, colaciones, etc.) se registraban en unos libros siguiendo una práctica habitual en las grandes cancillerías de la época (pontificia, imperial, real) y gracias a dichos registros conservados podemos conocer la actividad burocrática de una oficina expedidora de documentos como era la cancillería episcopal valentina en los siglos bajomedievales.

La lectura paciente de las diversas letras copiadas en los registros del obispo Hug de Llupià (1398-1427) nos ha permitido conocer las personas que componían la casa, corte y cancillería de este obispo, con sus distintos cargos, oficios, domésticos y familiares que en ella ejercieron sus funciones al servicio de la administración de la diócesis (vicario general, oficial, secretario del obispo, escribanos, abogados, procuradores, nuncios, oficial de Xàtiva, etc.) y del prelado (mayordomo, ayudante de cámara, repostero, limosnero, confesor, beneficiados, portero, parientes del obispo, etc.) tanto en Valencia como en los lugares que pertenecían a la mitra. Nos hemos servido de cinco registros conservados en el Archivo Diocesano de Valencia

'Ignacio PÉREZ DE HEREDIA Y VALLE, Sínodos medievales de Valencia. Edición bilingüe, "Anthologica Annua", 40 (1993) pp. 477-858 y tirada aparte en Roma, Publicaciones del Instituto Español de Historia Eclesiástica, 1994 (=Subssidia, 33).

${ }^{4}$ Estas decisiones las encontramos copiadas en los registros episcopales conservados en el Archivo Diocesano de Valencia (en lo sucesivo ADV), cuya serie comienza en 1316, aunque el primer registro conservado es de 1346-1347. Las letras episcopales de este primer registro han sido regestadas por $\mathrm{M}^{\mathrm{a}}$ José CARBONELl BORIA, El libro de colaciones de Ramón Gastón (1312-1347). Estudio crítico, Valencia 1986. Tesis de Doctorado inédita. Las de los dos siguientes han sido regestadas por $\mathrm{M}^{\mathrm{a}}$ Milagros CÁRCEL ORTí, Un registro de colaciones de la curia episcopal valentina (1349-1350), "Boletín de la Sociedad Castellonense de Cultura", LXVII (1991) pp. 181-262; ID., Un registro de colaciones del obispo Vidal de Blanes (13501359), "Estudis Castellonencs" (en prensa), respectivamente. Las letras en valenciano de todos estos registros han sido recogidas por $\mathrm{M}^{\mathrm{a}}$ Milagros CÁRCEL ORTí, La lengua vulgar en la administración episcopal valentina (siglos XIV-XV). Castellón, Sociedad Castellonense de Cultura, 1994 (=Obras de investigación histórica, LXVII). 
correspondientes a los años $1408,1412,1418,1421$ y $1425^{5}$, bastante representativos del pontificado de este prelado.

Los estudios sobre las cortes de los soberanos medievales de la antigua Corona de Aragón son escasos ${ }^{6}$. Abundan, en cambio, los relativos a diferentes cargos (mayordomos, alférez, funcionarios económicos, correos, etc.), oficios y personal de la cancillería ${ }^{7}$. Mucho más escasos son los estudios sobre las cortes episcopales en la misma Corona de Aragón ${ }^{8}$. Sobre el tema de la familia del obispo contamos con varios trabajos en diferentes paises, como Alemania ${ }^{9}$; Francia $^{10}$ para la diócesis de Besançon ${ }^{11}$; Italia

\footnotetext{
${ }^{5}$ ADV Sección I. Fondo III. Colaciones de beneficios. Caja 137/2 (año 1408), 138/1 (año 1412 ), 138/2 (año 1418), 138/3 (año 1421) y 139/1 (año 1425) respectivamente. En el registro de 1408 se copiaron trescientos noventa y siete documentos, en el de 1412 trescientos setenta y uno, en el de 1418 trescientos setenta y dos, en el de 1421 seiscientos seis y en el de 1425 cuatrocientos sesenta y siete, lo que da un total de dos mil doscientos trece documentos revisados.
}

${ }^{6}$ L. BATLlE y PRATS, Tres confesores del rey católico y la ciudad de Gerona, "Anales del Instituto de Estudios Gerundenses, 7 (1952) pp. 156-266. Hans SCHADEK, Die Familiaren der sizillischen and aragonischen Könige im 12. und 13. Jahrhundert, "Spanische Forschungen der Görresgesellschaft" 1. Reiheband, 26 (1971) pp. 201-348. ID. Los familiares valencianos de la Corona de Aragón en el siglo XIV, "Primer Congreso de Historia del País Valenciano", II, Valencia, 1980, pp. 513-518. Johannes VINCKE, Los familiares de la Corona Aragonesa alrededor del año 1300, "Anuario de Estudios Medievales", 1 (1964) pp. 333-351.

${ }^{7}$ Cfr. José Trenchs OdenA, Casa, corte y cancillería de Pedro el Grande (1276-1285), Roma, Consiglio Nazionale delle Ricerche, 1991 (= Sezione di studi storici "Alberto Boscolo", 3), p. 13 .

${ }^{8}$ Para Barcelona: José M. MARTí BONET, Las visitas pastorales y los "Comunes" del primer año del pontificado del obispo de Barcelona Ponç de Gualba (a. 1303), "Anthologica Annua", 28-29 (1981-1982) pp. 671-824, concretamente p. 641. Este mismo trabajo se publicó posteriormente con el mismo título en forma de libro, Barcelona, 1983; la curia episcopal se trata en la p. 61. Para Girona: Josep M. MARQuĖS I PlanAgumÀ, El govern de la diòcesi $i$ de la bisbalia de Girona (1334-1362), "Estudis del Baix Empordà", 12 (1993) pp. 85-105. Para Valencia: $\mathrm{M}^{\mathrm{a}}$ Milagros CÁRCEL ORTí, Notas de cancillería en los registros episcopales de obispo Hugo de Fenollet (1348-1356), "Historia. Instituciones. Documentos. Homenaje al Prof. Luís Núñez Contreras", 19 (1992) pp. 133-147; en las pp. 135-138 se ofrecen los cargos y funcionarios de la curia. Para Zaragoza: Pilar Pueyo Colomina, Algunas noticias sobre el registro de actos comunes del arzobispo de Zaragoza, Guillermo de Agrifolio (1347-1350), "Signo. Revista de Historia de la Cultura Escrita", 1 (1994) pp. 77-90.

${ }^{9} \mathrm{~F}$, Burgard, Familia Archiepiscopi. Studien zu den geistlichen Funktionsträgern Erzbischof Balduins von Luxemburg (1307-1354) (1992).

${ }^{10}$ É. FOURNIER, Nouvelles recherches sur les curies, chapitres et Universités de l'ancienne Église de France, Arras, 1942.

${ }^{\prime \prime} \mathrm{H}$. de FAjet DE CASTEljau, La famille de Guillaume de la Tour, archevêque de Besançon, révelée par une charte de Rosières (1219), "Mélanges à la mémoire du P. Anselme Dimier", 3, II, pp. 645-650. 
para las diócesis de Ferrara ${ }^{12}$, Pádua ${ }^{13}$, Parma $^{14}$ y Verona ${ }^{15}$. En el estudio introductorio que acompaña la edición de los registros episcopales de las diócesis inglesas y en la colección de las English Episcopal Acta se suele dedicar un apartado a the bishop's staff and household y a the bishop's 'chancery' ", aunque también existen trabajos específicos sobre el tema. De ambos casos tenemos sobre las diócesis de Bath y Wells ${ }^{17}$, Canterbury ${ }^{18}$,

${ }^{12}$ Enrico PeVerada, La visita pastorale del vescovo Francesco Dal Legname a Ferrara (1447-1450), "Deputazione Provinciale Ferrarese di Storia Patria-Serie Monumenti", VIII (1982). ID. La "familia" del vescovo e la curia a Ferrara nel sec. XV, "Vescovi e diocesi in Italia dal XIV alla metà del XVI secolo. (Atti del VII convegno di storia della Chiesa in Italia (Brescia, 21-25 settembre 1987)", II, Roma, 1990, pp. 601-660. Entre las pp. 612-613 publica un documento que trata de la composición de la domus del obispo, titulado Salaria famulorum episcopatus, que contiene el elenco de los cargos, los nombres de los que los desempeñan y los salarios que perciben en 1426.

${ }^{13}$ Paolo Sambin, La "familia" di un vescovo italiano del '300 [Ildebrando Conti $† 1352$ ], "Rivista di storia della Chiesa in Italia", 4 (1950), pp. 237-247.

${ }^{14}$ Gianluca BATTIONI, Sacramoro da Rimini e il governo della diocesi parmense (1476-1482), "Parma e l'umanesimo italiano", Atti del Convegno internazionale di studi umanistici, a cura di P. Medioli Masotti, Padova, 1986, pp. 55-73.

${ }^{15} \mathrm{M}$. Cipriani, Per lo studio dell'episcopato di Ermolao Barbaro (1453-1471): la "familia" e alcune linee dell'attività pastorale. Il "Liber Collationum" (1454-1463): analisi, edizione parziale e regestazione, Tesi di laurea. Università degli Studi di Verona, Facoltà di Magistero. a.a. 1990-91, rel. G. de Sandre Gasparini.

${ }^{16} \mathrm{Hasta}$ el momento han aparecido los siguientes títulos de la gran colección de documentos episcopales originales English Episcopal Acta. vol. 1: Lincoln [1067-1185], ed. D.M. SMITH [London 1980]; vol 2/3: Canterbury, vol. 2: 1162-1190, ed. C.R. CHENEY and B.E.A. JONES, vol. 3: 1193-1205, ed. C.R. CHENEY and C. JOHN, 1986. Vol. 4: Lincoln 1186-1206, ed. D.M. SMITH. (London 1986). Vol. 5: York 1070-1154, ed. J.E. BURTON, 1988. Vol. 6: Norwich 1070-1214, ed. C. HARPER-BILL. 1990. Vol. 7: Hereford 1079-1234, Oxford 1993. Vol. 8: Winchester 1070-1204, ed. M.J. FrankLIN, Oxford 1993. Vol. 9: Winchester 1205-1238, ed. N. VINCENT, 1994. Vol. 10: Bath and Wells 1061-1205, ed. Frances M.R. RAMSEY, Oxford, University Press for the British Academy, 1995. Vol. 11: Exeter 1046-1184, ed. F. BARLow, Oxford, University Press for the British Academy, 1996. Vol. 12: Exeter 1186-1257, ed. F. BARLOW, Oxford, University Press for the British Academy, 1996. Vol. 13: Worcester 12181268, ed. by Ph. M. Hoskin, Oxford, University Press for the British Academy, 1997. Vol. 14: Coventry and Lichfield 1071-1159, ed. by M.J. FRANKLIN, Oxford, University Press for the British Academy, 1997. Vol. 16: Coventry and Lichfield 1160-1182, ed. by M.J. FrankLIN, Oxford, University Press for the British Academy, 1998.

${ }^{17} \mathrm{R}$.W. DUNNING, The Households of the bishops of Bath and Wells in the Later Middle Ages, "Somersetshire Archaeological and Natural History Society Proceedings", 110 (1966) pp. 24-39.

${ }^{18} \mathrm{~N}$. AdAmS-Charles Donahue, Jr. (eds.), Select cases from the ecclesiastical courts of the Province of Canterbury ca. 1200-1301, London, Selden Society Publications 95 for 1978-1979 (1981). Kathleen MAJOR, The "familia" of Archbishop Stephen Langton, "The English Historical Review", XLVIII (1933) pp. 529-553. 
Lincoln $^{19}$, Salisbury ${ }^{20}$ y Worcester ${ }^{21}$. Más amplia es la bibliografía sobre las cortes y la familia de los reyes medievales ${ }^{22}$, así como de los papas ${ }^{23}$ y cardenales ${ }^{24}$.

Actualmente el nombre de familia sugiere inmediatamente relaciones de parentesco, pero es posible encontrar todavía el nombre de "familiar" del obispo referido a clérigos que lo sirven muy de cerca y conviven con él. Este es el sentido principal que consideramos, aunque haremos también referencia a los parientes del obispo. El fenómeno de la familiaritas en torno a los potentados es supranacional y excede asimismo cualquier límite regional. De tradición romana, los nuevos elementos que vienen a incrustrar-

\footnotetext{
19 Michael Burger, "Officiales" and the "familiae" of the Bishops of Lincoln, 1258-99, "Journal of Medieval History", 16 (1990) pp. 39-53.

${ }^{20}$ The Register of John Waltham, Bishop of Salisbury, 1388-1395. Ed. by T.C.B. TIMmINS, Woodbridge, Boydell Press for the Canterbury and York Society, 1994.

${ }^{21}$ Roy Martin, HAINES, The church and politics in fourteenth-century England: The career of Adam Orleton c. 1327-1345, London, Cambridge University Press, 1978; basa su estudio en registros episcopales y recompone la "familia". ID. Calendar of the Register of Simon de Montacute, bishop of Worcester, 1334-1337, Worcester, The Worcester Historical Society, 1996 (=New Series, 15)

${ }^{22}$ Para Castilla: J.C. PARSONS, The court and household of Eleanor of Castille in 1290. An edition of British Library Add. Ms. 35294, with introduction and notes, Toronto, Pont. Institute of Mediaeval Studies, 1977 (=Studies and Texts, 37). Para Navarra: R. GarCía ARANCón, Clérigos del séquito real en Navarra (1384-1387), "Príncipe de Viana", 54 (1994), pp. 403-416. Para Francia entre otros: André LAPEYRE-Rémy SCHEURER, Les notaires et sécretaires du roi sous les règnes de Louis XI. Charles VIII et Louis XII (1461-1515), notices personnelles et généalogiques, Paris, 1978 (= Collection de documents inédits sur l'histoire de France), 2 vol. Georges, MiNOIS, Le confesseur du roi, les directeurs de conscience sous la monarchie française, Paris 1988. Abbé Guillaume Mollat, L'aumônier du roi de France du XIII" au XV siècle, "Académie des inscriptions et belles-lettres, comptes-rendus de séances", 1939, pp. 514 525. Françoise ROBIN, Les chapelles seigneuriales et royales françaises au temps de Louis XIV "La France à la fin du $X V^{*}$ siècle: renouveau et apogée. Actes du colloque international du CNRS (Tours, 1983)", publiés sous la dir. de Bernard Chevalier et Philippe CONTAMINE, Paris, 1985. Xavier de la SELLE, Le service des ames à la cour. Confesseurs et aumôniers des rois de France du XIII' au XV' siècle, Paris, 1955 (=Mémoires et Documents de l'École des Chartes, 43).

${ }^{23}$ Vid. entre otros Bernard GUILlEMAIN, Les chapelains d'honneur des papes d'Avignon, "Mélanges d'archéologie et d'histoire. École Française de Rome", 64 (1952) pp. 217-288. ID La cour pontificale d'Avignon (1309-1376), étude d'une société, Paris, 1962. Reimpresión 1966 (Bibliothèque des Écoles françaises d'Athènes et de Rome). Bernhard SCHIMmELPFENNIG, Die Organisation der päpstliche Kapelle in Avignon, "Quellen und Forschungen", 50 (1971) pp. 80111 .

${ }^{24}$ Vid. entre otros A. Paravicini Bagliani, Cardinali di curia e "familiae" cardinalizie dal 1227 al 1254, Padova, Editrice Antenore, 1972 (=Italia Sacra, 18-19). M. PELLEGRINI, Ascanio Maria Sforza: la creazione di un cardinale "di famiglia", "Gli Sforza, la Chiesa lombarda, la corte di Roma. Strutture e pratiche beneficiarie nel ducato di Milano (1450-1535)", a cura di G. ChitTolini, Napoli, 1989, pp. 268 ss.
} 
se en la faz de la familiaridad medieval proceden ante todo del campo eclesiástico y germánico, siendo en el siglo XIII cuando la familiaridad cobró renovado y fuerte impulso en la Curia romana. Al tiempo que se extendía el ámbito de atribuciones y tareas de la corte papal, tanto el Sumo Pontífice como los Cardenales, impulsados por la necesidad de abarcar esta ingente masa de trabajo, se rodeaban de familiares en medida creciente, recompensándolos ante todo, dada su frecuente condición de clérigos, mediante la concesión de prebendas y beneficios eclesiásticos. Estos familiares, por hallarse empleados en menesteres concernientes a la totalidad de la Iglesia, podían percibir las rentas de sus beneficios aunque no residiesen personalmente en sus iglesias. Reyes, príncipes y obispos solicitaron del Papa que dispensase a sus clérigos del deber de residencia, por necesitarlos ellos para la modernización de su corte y para su capilla o demás servicios de culto, de manera que dichos clérigos dispensados conservaron en adelante los ingresos económicos de sus prebendas. Con respecto a tales clerici domestici - o a una parte de los mismos, al menosfue ganando creciente carta de naturaleza la designación de familiares. Por lo tanto, ambas expresiones no poseen siempre la misma significación. Los familiares, cuando eran nombrados separadamente de los domestici, precedían a éstos en rango. Un domesticus, empero, podía elevarse más adelante hasta la categoría de familiaris, en cuyo caso solía ostentar luego el doble título de domesticus et familiaris ${ }^{25}$.

Muchos obispos muy activos entre los siglos XIV y XV, sobre todo italianos, provenían de ambiente curial, donde habían pasado una parte de su vida al servicio de cualquier pontífice, volviendo a la propia diócesis en el momento de la desaparición de su protector. Esto contribuiría en parte a la introducción de los usos cancillerescos pontificios en sus respectivas cancillerías episcopales (uso del signo rodado como modo de validación episcopal, fórmulas del tenor documental, modos de registración, aplicación de tasas a los documentos, tipología documental, etc. $)^{26}$.

\footnotetext{
${ }^{25}$ Cfr. Johannes VINCKE, ob.cit. pp. 333-335.

${ }^{26} \mathrm{Cfr}$. COMmission InTERnationale de Diplomatique, Der Einfluss der päpstlichen Kanzlei auf das europäische Urkundenwesen-Hoch- und Spätmittelalter. L'influence de la chancellerie pontificale sur les chancelleries en Europe aux $X I I^{\prime}-X V^{\prime}$ siècles, "Archiv für Diplomatik" (en prensa).
} 
También la familia del obispo ${ }^{27}$ estaba compuesta por un complejo y variado grupo de hombres, de la diócesis y de fuera, eclesiásticos y laicos, de gobierno y de cultura, doctores, juristas y médicos, estudiantes, notarios y escribanos, etc. que estaban ligados al obispo por lazos de fidelidad, sin excluir su amistad, y que le servían en la curia $^{28}$ y en la "domus" ${ }^{29}$ con generosa colaboración.

\section{CASA, CORTE Y CANCILLERÍA DEL OBISPO HUG DE LLUPIÀ}

Al quedar vacante la mitra valentina por defunción de su titular, Jaime de Aragón, el papa Benedicto XIII la propuso al dominico, Vicente Ferrer, que la rehusó. A petición del rey Martín I, dicho papa nombró obispo de Valencia el 28 de noviembre de 1397 a Hug de Llupià, que era obispo de Tortosa (1379-1397), el cual llegó a la diócesis el 19 de agosto de $1400^{30}$.

El nuevo obispo, descendiente de los caballeros que sirvieron a los reyes de Mallorca, era hijo de don Pedro de Llupià y hermano de don Ramon de Llupià, señores de la villa de Bagès y castillo de Monistrol, en el condado de Rosselló, diócesis de Elna, y tanto por el señorío de los suyos como por ser natural de la villa fue llamado Hug de Bagès ${ }^{31}$.

Mandó redactar el Liber Instrumentorum, conservado en el Archivo de la Catedral de Valencia, en el que se recopilan documentos relativos a

${ }^{27}$ J. DESHuSSES, Familiers des évêques, "Dictionnaire de droit canonique". IV, Paris, 1949, col. 809-810.

${ }^{28}$ Algunos familiares acompañan al obispo en la visita pastoral, ya que en las actas se da cuenta entre otras cosas del número de los componentes de su familia.

${ }^{29} \mathrm{La}$ diócesis de Valencia dependía administrativamente del metropolitano de Tarragona por lo que debía regirse por las constituciones de los concilios provinciales. En el segundo concilio que celebró el arzobispo Benet de Rocabertí en 1266 manda en la constitución XXX Quod episcopi faciant legi ad mensam. "Item ne solum fauces sumant cibum, sed aures audiant verbum Dei et cessent vaniloquia et tumultus, statuimus quod singuli episcopi, in palaciis suis, dum comedunt, ad mensam faciant sibi legi [...]" (Cfr. Josep Ma PONS GURI, Constitucions Conciliars Tarraconenses, "Analecta Sacra Tarraconensia", XLVIII (1975) p. 155. Existe tradución al catalán por Josep M. MARQUĖS, Concilis Provincials Tarraconenses, Barcelona, 1994, p. 119)

${ }^{30} \mathrm{Cfr}$. Arturo Llin Cháfer, Arzobispos y obispos de Valencia, Valencia, 1996, pp. 69-70.

${ }^{31}$ Cfr. Elías Olmos Canalda, Los prelados valentinos, Valencia, 1949, pp. 102-107. 
donaciones, legados, amortizaciones, diezmos, permutas y otros asuntos de interés económico para el cabildo y la sede valentina. En 1408 asistió al Concilio de Perpinán ${ }^{32}$ convocado por Benedicto XIII, del que era partidario Hug de Llupià. Celebró sínodo diocesano en 1400, 1404 (del cual sólo consta la convocatoria y se presume le celebración en la fecha prevista), 1408 y $1422^{33}$. Murió este obispo el 11 de abril de 1427 y fue sepultado en la capilla mayor de la catedral.

\section{La cancillería}

\section{I.1. Vicario general}

1. Joan de Moya (1408-1421), "in decretis licenciatus, canonicus Barchinone... vicarius in spiritualibus et temporalibus generalis". En un documento expedido el 2.VI.1408 aparece citado como "nostrum convicarium"34. El 29.IX.1408 fue nombrado por el obispo administrador del hospital construido en Alzira por Jaume Scuder y encargado de la cura de almas y régimen del mismo y percibiría 100 sueldos al año ${ }^{35}$.

2. Bernat de Carcí (1408-1421), "in legibus licenciatus, canonicus Valencie... vicarius in spiritualibus et temporalibus generalis" ${ }^{136}$.

3. Joan Martorell (1408), "in decretis bacallarius, canonicus Valencie... vicarius in spiritualibus et temporalibus generalis" ${ }^{37}$.

4. Joan Gastó (1408-1425), el 10.III.1408, siendo "clerico, in decretis licenciato", fue nombrado por el obispo vicario general "in regimine oficii vicarii generalis... propterea citra revocacionem aliorum vicariorum generalium per nos constitutorum" ${ }^{38}$. El 14.VII.1421 el obispo le concedió la parroquia de Gandia, y el documento lo cita como "licenciato in decretis,

\footnotetext{
${ }^{32}$ En el registro de 1408 aparece una anotación en el margen inferior, casi en el borde de la hoja, que dice: "Diluns, a XV dies d'octubre, any MCCCCVIII se'n anà lo senyor al Papa. a Perpinyà". (Cfr. ADV Sección I. Fondo III. Colaciones de beneficios. Caja 137/2, fol. 85 v.).

${ }^{33}$ Vid. Ignacio PÉREZ DE HEREDIA Y VALLE. ob. cit., pp. 326-358.

${ }^{34}$ ADV Sección I. Fondo III. Colaciones de beneficios. Caja 137/2, fol. 56 r.

${ }^{35}$ Ibid. Caja 137/2, fol. 83 r.

${ }^{36}$ Ibid. Caja 138/1, fol. 2 r.

${ }^{37}$ Ibid. Caja 137/2, fol. 3 v

${ }^{38}$ Ibid. fols. 25 r.- v.
} 
canonico Valencie"39. El 28.II.1425 el obispo lo cesó de su cargo en un acto en que revocó a sus cinco vicarios generales ${ }^{40}$.

5. Gil Sanç Muñoz (1408), el 14.X.1408 fue nombrado vicario general y se le cita como "canonicum Valencie"4l.

6. Galderic de Soler (1412-1425), "clericus, in decretis licenciatus... vicarius in spiritualibus et temporalibus generalis" ${ }^{42}$. En 1418 aparece como "in decretis licenciatus, rector ecclesie de Castalla... vicarius in spiritualibus et temporalibus generalis"43. El 30.I.1425 le fue concedida por un año la rectoría de Castalla con licencia para absolver casos reservados ${ }^{4}$. El 28.II de ese año el obispo lo cesó de su cargo en un acto en que revocó a sus cinco vicarios generales. ${ }^{45}$

7. Pere de Darnius (1418-1425), "in decretis licenciatus, canonicus Gerundensis... vicarius in spiritualibus et temporalibus generalis" ${ }^{46}$. El 1.I.1418 fue nombrado rector de Biar Pere de Darnius ${ }^{47}$, pero el 8 del mismo mes le fue concedida la cura de almas de dicho lugar por un año a Bertomeu Pérez de Molina, beneficiado de la colegiata de Xàtiva ${ }^{48}$. El miércoles 28.II.1425, en hora de vísperas, el obispo lo cesó de su cargo en un acto en que revocó a sus cinco vicarios generales y allí se le cita como "canonicum Valencie"49.

8. Pere Amorós (1418-1425), anteriormente había sido oficial de Xàtiva, pero la primera vez que aparece como vicario general es en un documento del 17.II.1418. ${ }^{50}$ El 5.IV.1421 Pere Amorós, "decretorum doctori, clerico", permutó su beneficio en el altar o capilla de S. Dionisio de la catedral, instituido por Jaume de Pertusa, canónigo y paborde de la

\footnotetext{
${ }^{39}$ Ibid. Caja 138/3, fols. 70 v.-71 r.

"Il Ibid. Caja 139/1, fol. 25 v.

"Ibid. Caja 137/2, fol. 85 v.

t'Ibid. Caja 138/1, fol. 7 v.

${ }^{43}$ Ibicl. Caja 138/2, fol. 23 v.

"Ibíd. Caja 139/1, fol. 13 v.

${ }^{45}$ Ibid. fol. $25 \mathrm{v}$.

${ }^{46}$ Ibied. Caja 138/2, fol. $11 \mathrm{r}$.

${ }^{47}$ Ibied. fol. $5 \mathrm{r}$.

${ }^{48}$ Ibicl. fol. $7 \mathrm{v}$.

49Ihid. Caja 139/1, fol. 25 v.

${ }^{50} I$ lbid. Caja 138/2, fol. 29 v.
} 
misma, con el del presbítero Domènec Navarro, beneficiado en la capilla de S. Pedro en la catedral ${ }^{51}$ y el 21 de ese mismo mes permutó su rectoría de Alfafar con Guillem Pla, beneficiado de tres beneficios: el de S. Dionisio en la catedral, el del altar mayor de S. Martín y el del Espíritu Santo en el monasterio de S. Vicente ${ }^{52}$. El 28.II. 1425 el obispo lo cesó de su cargo en un acto en que revocó a sus cinco vicarios generales en lo espiritual y temporal y a sus dos vicarios generales capitulares ${ }^{53}$.

9. Simó Salvador (1425), el 28.II.1425 el obispo lo cesó de su cargo en un acto en que revocó a sus cinco vicarios generales y allí se le cita como "decretorum doctorem, canonicum et archidiaconum Valencie" ${ }^{54}$. No lo hemos visto expidiendo ningún otro documento.

10. Miquel Molsós (1425), fue nombrado vicario general el 28.II.1425, siendo "decretorum doctori, preposito secularis ecclesie collegiate ville de Oriola, diocesis Cartaginensis" ${ }^{15}$, el cual prestó juramento el día primero del siguiente mes a la hora de tercia ${ }^{56}$.

\subsection{Lugarteniente del vicario general}

1. Antoni de Caldes (1425). El 3.III.1425 el obispo manda a todos los rectores de la diócesis que atiendan bien al vicario general Antoni de Caldes si va a cualquier iglesia de la diócesis a hacer procesión para impetrar la lluvia ${ }^{57}$. El lunes 4 .VI de ese año el vicario general Miquel Molsós "intendens recidere a civitate Valencie iturus versus Ayora, constituhit locumtenentem suum in dicto oficio Vicariatus generalis cum illa eadem potestatem quam sibi dedit reverendus dominus episcopus Valentinus in sua comissione honorabilem virum dominum Anthonium de Calidis, in decretis bacallarium, canonicum Valencie, dum ipse nunch et per futurum

\footnotetext{
${ }^{51}$ Ibid. Caja 138/3, fols. 29 v. -30 r

${ }^{52}$ Ibid. fols. 28 v. -29 r.

${ }^{53}$ Ibid. Caja 139/1, fol. 25 v.

${ }^{54}$ Ibid. fol. $25 \mathrm{v}$.

${ }^{55}$ Ibid. fol. $26 \mathrm{r}$.

solbid. fol. $27 \mathrm{r}$.

${ }^{57}$ Ibid. fol. $27 \mathrm{v}$.
} 
dictus vicarius absens fuerit a dicta civitate Valencie et non amplius"58 y lo vemos expidiendo documentos hasta mediados de noviembre de ese año.

\subsection{Oficial}

1. Joan Gastó (1425), el 4.I.1425 el obispo concedió licencia de sepultura dentro de la iglesia de Gandia a Joan Gastó "in decretis licenciato, canonico et officiale nostro Valentino ac rectori ecclesie de Gandia", donde había fundado dos aniversarios perpetuos de $10 \mathrm{~s}$. y había dejado 100 florines para la fábrica de dicha iglesia y capilla de Sta. Catalina ${ }^{59}$.

\section{I.4. Lugarteniente del oficial de Valencia}

1. Jaume Sala (1408), aparece como "dilecto Jacobo Sala, presbitero, locumtenenti officialis nostri Valencie" en un documento en donde el obispo le manda que restituya a Pere Avellà, mercader de Valencia, procurador de Joan Avellà, su hijo y beneficiado en Dénia, 2 florines de oro de Aragón que se le tomaron con motivo de la visita pastoral realizada a dicho lugar ${ }^{60}$.

2. Guillem Sala (1421), el 23.V.1418 le fue concedida una permuta a Guillem Sala, "presbitero Valencie, bacallario in decretis", beneficiado en el altar mayor de S. Juan del Mercado, bajo la invocación de Sta. Lucía, con Pere Bonaig, beneficiado en el altar mayor de Sta. Cruz ${ }^{61}$. El 9. VIII de ese año le sustituyó Joan Castan para celebrar durante un año en el beneficio de Sta. Cruz ${ }^{62}$. El 22.X.1421 el obispo concedió a Guillem Sala, "presbitero, in decretis bacallario, familiari nostro" el beneficio de S. Blas en Albalat de la Ribera ${ }^{63}$. En un documento fechado el 14.XII de ese año se le cita como "locumtenens oficialis nostri Valencie" ${ }^{64}$.

3. Bertomeu Salat, "lo canonge" (1412) ${ }^{65}$.

\footnotetext{
${ }^{58}$ Ibid. fol. $65 \mathrm{r}$.

${ }^{59}$ Ibid. fol. $3 \mathrm{v}$.

${ }^{60}$ Ibid. Caja 137/2, fol. 41 v.

"Il Ibid. Caja 138/2, fols. 65 v. -66 r.

"IlItid. fol. $80 \mathrm{v}$.

${ }^{63}$ Ibicl. Caja 138/3, fols. 106 v.-107 r.

${ }^{a}$ Ibid. fols. $117 \mathrm{v} .-118 \mathrm{r}$.

${ }^{65}$ Ibid. Caja 138/1, fols. 26 v. -28 r.
} 


\section{I.5. Secretario del obispo}

1. Pere Llorenç (1408-1412), aparece citado en un documento como "dilectum secretarium nostrum... notarium"66. El 9.VII.1408, siendo beneficiado en Alaquàs, se le concede una licencia para celebrar por un año en la catedral en sustitución de Pere Conill, beneficiado ${ }^{67}$. El 11 del mismo mes y año obtiene de nuevo otra licencia como la anterior en sustitución de Pere Castellar ${ }^{68}$. El 9.VIII otra igual en sustitución de Nicolau Martí, clérigo $^{69}$. El 23.II.1412 se le concede dispensa para atender el beneficio de S. Juan del Hospital ${ }^{70}$.

\section{I.6. Escribano de la Curia del Vicariato}

1. Pere Llorenç (1408-1425). Además de secretario del obispo, se le cita como "dicte scribanie [Vicariatus] scriptori"71. En una toma de posesión de un beneficio hecha en 1425, anota de su mano en un registro al margen de un dcumento "iam est traditam in forma publica per me Petrum Laurencii"72.

\section{I.7. Escribano de la curia del Oficialato}

1. Berenguer d'En Camps (1408), en un documento aparece nombrado como "dilecto nostro, scriptori curie predicte [scribanie Officialatus] ${ }^{73}$, y en un documento fechado el 14.VII.1421 actua como testigo y es "notarius" $"$.

\footnotetext{
"Ibid. Caja 137/2, fol. 20 r.

${ }^{67}$ Ibid. fol. 62 r.

${ }^{18}$ Ibid. fol. $62 \mathrm{v}$.

${ }^{69} I$ Ibid. fol. $67 \mathrm{v}$.

${ }^{70}$ Ibíd. Caja 138/1, fol. 15 r.

${ }^{71}$ Ibid. Caja 137/2, fol. 69 v.

${ }^{72}$ Ibid. Caja 139/1, fol. 112 v

${ }^{73}$ Ibid. fol. $50 \mathrm{v}$.

${ }^{74}$ Ibid. Caja 138/3, fol. 62 v.
} 


\section{I.8. Abogado fiscal de la curia del Oficialato}

1. Bernat Bonhome (1408), aparece citado como "licenciato in decretis, advocato fischali curie Oficialatus nostri" el 28.VI.1408, en que el obispo le asigna "pro salario oficii advocacionis... in et super emolumentis et iuribus fischalibus quibuscumque curie... quinquaginta florenos auri anno quolibet dum oficium exerceritis" ${ }^{75}$. sus oficiales

I.9. Receptor de los emolumentos del fiscal de la curia del obispo y

1. Francesc Esteve (1425), actuó como testigo en el juramento del cargo de Miquel Molsós el 1.III.1425 y se le cita como "presbiter, elemosinarius dicti domini episcopi". Ese mismo día fue nombrado receptor de los emolumentos del fiscal de la curia del obispo y de sus oficiales, y juró su cargo ${ }^{76}$.

\section{I.10. Procurador general del obispo}

1. Esteve Valença (1412), el 2.IV.1412 el obispo concedió al "dilectus procurator generalis noster... civis Valencie" la alcaidía del castillo y lugar de Garg, del que será alcaide y baile, percibiendo un salario de 50 libras anuales de las rentas de dicho lugar ${ }^{77}$.

2. Jaume Valença (1425), el 30.IV.1425 el obispo mandó a todos los arrendadores de los derechos decimales pertenecientes a la mensa episcopal, que paguen a su "procurador nostre general" las cantidades debidas del precio de sus arrendamientos ${ }^{78}$.

\footnotetext{
${ }^{75}$ Ibid. Caja 137/2, fol. 64 r.

${ }^{76}$ Ibid. Caja 139/1, fol. 27 r.

${ }^{77}$ Ibid. Caja 138/1, fols. 91 v. -92 r.

${ }^{78}$ Ibid. Caja 139/1, fols. 55 v. -56 r.
} 
I.11. Procurador de los pobres y de las causas pias de la ciudad y de la diócesis

1. Pere Ros (1408-1412), aparece citado en los documentos de 1408 como "presbitero, Christi pauperum et piarum causarum in civitate et diocese nostra Valencie generali procuratori" ${ }^{79}$. En 1412 se le cita como "in decretis bacallario" en un documento en que presenta cuentas al obispo de $3.516 \mathrm{~s}$. y $11 \mathrm{~d}$. que por razón de su administración recibió desde el 11.I.1408 hasta el 22.IX de ese año ${ }^{80}$.

\section{I.12. Procurador y colector de los censales del obispado}

1. Domènec de Molinos (1408), en un albarán de rendición de cuentas ante el obispo hecho el 28.IV.1408 aparece citado como "amat nostre En Domingo de Molinos, notari de València, procurador e col-lector dels censals de la nostra bisbalia"81.

\section{I.13. Representante ocasional del obispo}

1. Francesc Daries (1425), el 20.IX.1425 el obispo mandó a Francesc Daries, "canonico et preposito sedis nostre Valentine" visitar la abadía del rector de Morvedre, que necesita reparación ${ }^{82}$.

\section{I.14. Vicario general capitular}

1. Pere Figuerola (1425), el miércoles 28.II.1425, después de vísperas, el obispo revocó en sus cargos a todos sus vicarios generales capitulares, entre ellos a Pere Figuerola, "decretorum doctorem" y a

2. Antoni de Caldes (1425), "in decretis bacallarium" y nombró a:

3. Joan Gastó (1425), "in decretis licenciatum, canonicum Valencie" y a Simó Salvador.

\footnotetext{
${ }^{79}$ Ibid. Caja 137/2, fol. 70 v.

${ }^{80}$ Ibid. Caja 138/1, fol. 79 r.

${ }^{81}$ Ibíd. Caja 137/2, fols. 45 r.-v.

${ }^{82}$ Ibid. Caja 139/1, fol. 114 v.
} 
4. Simó Salvador (1425), "decretorum doctorem, archidiaconum" ${ }^{83}$.

\section{I.15. Abogado fiscal del obispo}

1. Ramon Cirera (1408), en la documentación se le cita como "licenciato in decretis" y el 28.VI.1408 el obispo le asigna como salario por su trabajo de abogacía sobre los emolumentos y derechos fiscales de dicha Curia 50 florines de oro por cada año que ha estado en su cargo ${ }^{84}$.

\section{I.16. Nuncio jurado de la Curia del Oficialato}

1. Pere Roiç (1408), "nuncius iuratus curie Oficialatus Valencie"85.

2. Guillem Vermell (1418), el miércoles 5.I.1418, a la hora de tercia, fue enviado por el obispo Guillem Vermell, "nuncius iuratus curie Oficialatus Valencie," a entregar personalmente "quandam cedulam" a los vicarios generales, convicarios entre sí: Bernat Carcí, Joan de Moya, Pere de Darnius, Galderic de Soler, Pere Amorós y Joan Gastó para que no reciban ninguna permuta o renuncia del beneficio de Joan Alcover instituido en la ermita del Salvador de Alzira ni confirmen el derecho de patronato del beneficio de S. Matías y Sta. Lucía instituido en la iglesia de $S$. Juan del Mercado $^{86}$. cie $^{1187}$.

3. Pere Gurrea (1418), "nuncius iuratus curie Oficialatus Valen-

4. Joan Punyet (1425), el jueves 29.III. 1425 es enviado por el obispo Joan Punyet, "nuncius iuratus curie Oficialatus Valencie," a entregar "XII cartellos... duobus decim curatis ecclesiarum curatarum civitatis Valencie, primo curato Sancti Petri, deinde aliis sequentibus curatis dicte civitatis", relativos a una constitución publicada en "lo sacre concili de Tarragona... sobre lo portar de les vestidures e forradures de pells e cugulles de caperons e robes feses dels preveres de la provincia de Tarragona, en la qual

\footnotetext{
${ }^{83}$ Ibíd. fol. $26 \mathrm{v}$.

${ }^{84}$ Ibid. Caja 137/2, fol. 64 r.

${ }^{85}$ Ibid. fol. $63 \mathrm{v}$.

${ }^{86}$ Ibid. Caja 138/2, fol. 3 v.

${ }^{87}$ Ibid. fol. 70 r.
} 
constitució són posades certes penes a aquells qui no observaran sobre les dites coses la dita constitució, perque us ho notificam per ço que no caygats en les penes sobredites, les quals seran executades com no.s puxen remetre segons porets veure en la dita constitució, la qual vos mostrarà l'onorable oficial de València si veure-la voldrets" 88 .

5. Joan Besora (1425), el miércoles 20.V.1425 fue enviado Joan Besora, "nuncius iuratus curie Oficialatus Valencie," a entregar una letra a la priora del monasterio de Sta. María Magdalena de Valencia ${ }^{89}$. Más adelante aparece con el nombre de Domènec.

\section{I.17. Mensajero ocasional}

1. Bernat Garcés (1408-1425), el vicario general le concedió el 1.III.1408 una licencia para celebrar por un año en sustitución de Arnau Çamorera, beneficiado en S. Juan del Hospital ${ }^{90}$. El 30.IV de ese año "fon tramés per presentar la letra [citatio sinodi] als rectors e beneficiats del bisbat"91 y se le concedió además la cura de almas por dos años en la iglesia de Canet, porque no tenía ningún beneficio ${ }^{92}$. El lunes 30.VI.1425 Bernat Garcés, "prevere e vicari de Agres" llevó una letra a los rectores de Cocentaina y Agres sobre permuta de beneficios ${ }^{93}$.

\section{I.18. Oficial de Xàtiva}

1. Bertomeu de Valls (1408-1412), el 6.II.1408 le es concedida una licencia para aumentar la dotación de una capellanía en el beneficio de Bernat Esteve en la iglesia mayor de Xàtiva ${ }^{94}$. El 26.IX de ese año se le cita como "presbitero, officiali nostro Xative" en un documento en que el obispo le asigna 10 libras sobre el diezmo de las moreras de Xàtiva, que ha

\footnotetext{
${ }^{88}$ Ibíd. Caja 139/1, fol. 40 v.

${ }^{89}$ Ibid. fols. 77 v. $-78 \mathrm{r}$.

${ }^{90}$ Ibid. Caja 137/2, fol. 18 v.

${ }^{91}$ Ibid. fol. $35 \mathrm{r}$.

${ }^{92}$ Ibid. Caja 137/2, fol. 44 v.

${ }^{93}$ Ibid. Caja 139/1, fol. 85 v.

${ }^{94}$ Ibid. Caja 137/2, fol. 12 r.-v.
} 
gastado en la reparación de la casa del obispo de dicha ciudad ${ }^{95}$. El 14.V.1412 es amonestado por el rector por no atender su beneficio ${ }^{96}$. Obtenía también un beneficio en Alcoi, del cual es sustituido el 18.VIII de ese año por Joan de Matarredona ${ }^{97}$, el cual volvió a obtener una licencia para celebrar por un año hasta 10 libras en el mismo beneficio el 27.I. $1418^{98}$. El 3.X.1412 de ese año es revocado en su cargo, ya que es nombrado Pere Amorós ${ }^{99}$. El 6.VI.1418 aparece citado como "canonico ecclesie collegiate civitatis Xative" y se le concedió licencia para permutar su beneficio de S. Marcos con Pere Mathes, beneficiado en el de los Stos. Felipe y Santiago de dicha iglesia ${ }^{1(0)}$.

2. Pere Amorós (1412), el 3.X.1412 fue nombrado el "dilecto... clerico, decretorum doctori... vos officialem foraneum in dictis civitatis et locis ultra Xuquarum"101. El 24.I.1418 recibió del obispo la colación de la rectoría de Gallinera, siendo "clerico, decretorum doctori, familiari nostro" 102 .

3. Pere d'Arenys (1418-1425), el 3.X.1418, Pere d'Arenys, "canonico et officiali nostro Xative", rindió cuentas ante el obispo de los 1.454 s. que percibió desde el 2.IX.1417 hasta el día 2.X.1418 por razón de su oficio, de los que se quedará $1.000 \mathrm{~s}$. por su salario anual ${ }^{103}$. Ese mismo acto volvió a efectuarlo el 1.X.1421, de 891 s. 6 d. que percibió desde el 1.X.1420 hasta el último de septiembre de ese año, y como él debía cobrar $1.000 \mathrm{~s}$. por su salario de ese año y la quinta parte de los derechos por razón de su oficio, debe recuperar como complemento de su salario 287 s. 6 d.; quedando por pagarle del año 1419, 339 s. 6 d. que le asigna sobre dichos emolumentos del presente año, por lo que por los dichos dos años le quedan a deber por su salario $627 \mathrm{~s} .^{104}$. Ese mismo día respondió ante el

\footnotetext{
${ }^{95}$ Ibid. fol. $78 \mathrm{r}$.

${ }^{96}$ Ibíd. Caja $138 / 1$, fol. 32 r.

${ }^{97}$ Ibid. fol. $61 \mathrm{r}$.

${ }^{98}$ Ibid. Caja 138/2, fol. 18 r.

${ }^{99}$ Ibid. Caja $138 / 1$, fol. 75 r.

${ }^{100}$ Ibid. Caja 138/2, fols. 68 r. -69 r.

${ }^{101}$ Ibíd. Caja 138/1, fol. $75 \mathrm{r}$.

${ }^{102}$ Ibid. Caja 138/2, fols. 21 r.-v.

${ }^{103}$ Ibid. fol. $98 \mathrm{v}$.

${ }^{104}$ Ibid. Caja 138/3, fols. 98 r.-v.
} 
obispo de la administración de los bienes de Ramon Sanç, beneficiado en la colegiata de Xàtiva ${ }^{105}$. El 8.III.1425, se le concedió licencia de sepultura dentro de la colegiata, donde había fundado un aniversario y el documento le cita como "canonicus ecclesie collegiate et officialis noster civitatis Xative" 106

4. Tomás Gavarda (1425), el 18.III.1425 el obispo nombró a Tomás Gavarda, "clerico, in legibus licenciato, civitatis Xative... regentem dictum Oficialatum in dicta civitate Xative et ultra rivum Xuquari"107.

\section{La casa y corte}

\section{II.1. Los altos funcionarios}

\section{II.1.1. Mayordomo}

1. Ramon Botí (1412), el 2.I.1412 el obispo hace un donativo a su "maiordom nostre" de 500 florines de oro de Aragón en ayuda de su matrimonio, y por los servicios que le ha prestado ${ }^{108}$.

\section{II.1.2. Ayudante de cámara}

1. Joan Simó (1408-1425), el 2.V.1408, el obispo para premiar los servicios de un servidor suyo, coayudante de cámara, "recolentes servicia per te dilectum servitorem et fidelem coadiutorem camere nostre", le concede de manera graciosa 500 florines de oro de Aragón, de los emolumentos de la escribanía del Oficialato ${ }^{109}$. El 4 .VII.1412 se le cita como "presbiter, cubicularius reveredissimi domini episcopi" en un documento donde se concede una permuta entre Miquel del Miracle, canónigo de Urgell, beneficiado en el beneficio de la Aurora, en el altar mayor de la catedral, y Joan Simó, beneficiado de dos beneficios, el de S. Nicolás en la

\footnotetext{
${ }^{105}$ Ibid. fols. 97 v. -98 r.

${ }^{106}$ Ibid. Caja 139/1, fol. 36 r.

${ }^{107}$ Ibid. fol. 44 r.

${ }^{108}$ Ibíd. Caja $138 / 1$, fol. $1 \mathrm{v}$.

${ }^{109}$ Ibíd. Caja 137/2, fol. 50 v.
} 
iglesia mayor de Xàtiva, y el del altar mayor de Sto. Tomás ${ }^{110}$. Al mismo tiempo era beneficiado en el monasterio de Sta. María Magdalena, beneficio del que es sustituido en dos ocasiones: el 3.VI.1412 por Domènec Caravant $^{111}$ y el 13.IX.1418 por Joan Tortosa ${ }^{112}$. Por último, el 4.XII.1425 el obispo le concedió una prórroga por cuatro años más dispensándole de la colación del tercer beneficio que poseía en la catedral ${ }^{113}$.

2. Bernat Daries (1425), en un documento de 23.VI.1425 vemos como testigo a Bernat Daries, "cubicularius dicti domini episcopi"114. Tres días después, también actuando como testigo, se le cita como "clerico, de domo dicti domini episcopi Valentini"115.

\section{II.1.3. Repostero}

1. Lluís Fontfreda (1421), en un documento fechado el 14.VII.1421 aparece como testigo y es "presbiter". ${ }^{116}$ Dos días después se le concedió el beneficio de S. Gil en la iglesia de S. Lorenzo; una nota al margen dice "Nihil quia reboster de casa et de mandato domini"117.

\section{II.1.4. Limosnero}

1. Francesc Esteve (1425), el 1.III.1425 fue elegido Francesc Esteve, "presbiter, elemosinarius dicti domini episcopi, in receptorem emolumentorum fischalium Curie dicti domini episcopi et suorum oficialium"118.

\footnotetext{
${ }^{110}$ Ibid. Caja 138/1, fols. 50 v. -51 v.

"'Ibid. fol. $40 \mathrm{v}$.

"Ihid. Caja 138/2, fol. 95 v.

${ }^{113}$ Ibid. Caja 139/1, fol. 143 v.

${ }^{114}$ Ibicl. fol. $146 \mathrm{v}$.

${ }^{115}$ Ibid. fol. $148 \mathrm{r}$.

${ }^{116}$ Ibid. Caja 138/3, fol. 62 v.

${ }^{117}$ Ibid. fols. 65 v. -66 r.

${ }^{118}$ Ibid. Caja 139/1, fol. 27 r.
} 


\section{II.2. El personal-funcionario de la casa del obispo}

II.2.1. El vestido: el peletero

1. Joan Ferrer (1408), el 15.V.1408, el obispo, en compensación por los servicios prestados "per nos dilectum pelliparium nostrum", le concedió de manera graciosa 50 florines de oro de Aragón, de su cofre ${ }^{119}$.

\section{II.3. La capilla}

\section{II.3.1. Confesor}

1. Fray Nicolau Martorell (1412), el 6.IV.1412 el obispo nombró a este religioso, "ordinis minorum monasterii civitatis Valencie... in confessorem nostrum et nostre consciencie scrutatorem"120.

2. Fray Nicolau Puig (1425), el 28.II.1425, en que el obispo revocó en sus cargos a sus vicarios generales, actuó como testigo fray Nicolau Puig, "ordinis cisterciensis monasterii Sancti Vincencii, dicti domini episcopi confessore"121.

\section{II.3.2. Beneficiado}

1. Antoni Perallada (1418), el 12.VII.1418, el obispo le concedió licencia para celebrar "in sede Valencie sive in capella nostri palacii episcopalis", por lo que recibirá 12 libras. En el margen se anotó "gratis de mandato domini"122.

\footnotetext{
${ }^{119}$ Ibid. Caja 137/2, fol. 50 v.

12)Ibid. Caja 138/1, fol. 22 r.

I21 Ibid. Caja 139/1, fol. 26 v.

122Ibid. Caja 138/2, fol. 78 r.
} 


\section{II.4. Otros oficiales}

\section{II.4.1. Portero}

1. Arnau Agiert (1421), en un documento fechado el 12.XI.1421 aparece como testigo y se le cita como "porterius domini episcopi Valencie"123. $^{123}$.

\section{II.5. Familiares del obispo y miembros de "domo"}

1. Joan Canoni (1408), el 15.III.1408, el obispo nombró a Joan Canoni, "mercatori et civi Florencie... in familiarem nostrum et domus nostre recepimus et admitimus ac vos consorcio aliorum familiarium nostrorum continue residencium in domo nostra", por intercesión de Mateu de Berardo, mercader, ciudadano de Florencia ${ }^{124}$.

2. Pere Fabra (1408), en la documentación aparece como "scolari, familiari nostro". El 27.VIII.1408 manda el obispo a Pere Llorenç, escribano del Vicariato, que le entregue 50 florines de oro de Aragón al año en dos pagas en ayuda de sus estudios en un estudio general, del derecho de sello perteneciente a dicha escribanía ${ }^{125}$.

3. Joan de Ripoll (1408), aparece citado como "cavaller e familiar nostre" y el 24.IX.1408 el obispo manda a su procurador general que le pague 200 florines que le asigna sobre las rentas decimales del obispo "per molts agradables serveys per vós... a nós fets" ${ }^{126}$.

4. Joan Capella (1412), un documento fechado el 6.IV.1412 le cita como "clerico, diocesis Barchinone, familiari nostro" y en él se le concedió la colación del beneficio de $\mathrm{S}$. Pedro de la iglesia mayor de Xàtiva ${ }^{127}$.

5. Arnau Dezcorn (1412-1421), en un documento de 15.III.1412 se cita como "dilecto familiari nostro... clerico" y se le concede la colación del beneficio de Sta. María en la iglesia de S. Lorenzo ${ }^{128}$. El 26 de ese mismo

\footnotetext{
${ }^{123}$ Ibid. Caja 138/3, fol. 111 v.

${ }^{124}$ Ibid. Caja 137/2, fol. 69 v.

125Ibid. fol. $79 \mathrm{v}$.

126lbid. Caja 138/1, fol. $21 \mathrm{v}$.

${ }^{127}$ Ibid. fols. 17 v.-18 r.

${ }^{128}$ Ibid. fol. $20 \mathrm{r}$.
} 
mes el obispo pide al vicario general de Tortosa que acepte la resignación de dos beneficios que tiene Arnau Dezcorn en dicha ciudad ${ }^{129}$. El 16.VII.1421 le fue concedida la cura de almas del lugar de Madrona ${ }^{130}$.

6. Antoni Alcover (1418), el 3.VI.1418 fue concedida una permuta entre Antoni Alcover, "clericus, beneficiatus" en la ermita del Salvador de Alzira, y Pere Tapiol, beneficiado de S. Bartolomé de Valencia ${ }^{131}$. En el registro donde está copiado el documento se anotó al margen "nihil quia de domo".

7. Pere Tapiol (1418), el 10.V.1418 fue concedida una permuta de beneficios entre Pere Tapiol, clérigo, beneficiado de Sta. Quiteria en la iglesia de S. Bartolomé, y Antoni Alcover, beneficiado en la ermita del Salvador de Alzira ${ }^{132}$. Una nota al margen dice "nihil quia familiaris".

8. Bernat de Bas (1418), el 3.I.1418 el obispo concedió a Bernat de Bas, "dilecto familiari nostro", la rectoría de Gallinera ${ }^{133}$ y a los tres días la de Xul·lella ${ }^{134}$, vacantes por resignación y muerte respectivamente.

9. Pere Amorós (1418), el obispo concedió el 24.I.1418 a Pere Amorós, "decretorum doctor" la rectoría de Gallinera, vacante por resignación del rector anterior Bernat de Bas ${ }^{135}$.

10. Bertomeu Pérez de Molina (1418), el 8.I.1418 le fue concedida la rectoría de Biar, por un año, a Bertomeu Pérez de Molina, "presbitero, beneficiato in ecclesia collegiata Xative", en sustitución de Pere de Darnius. En el margen del documento registrado se anotó "nihil quia de domo"136.

11. Ramon de Sant Andreu (1418-1421), el 13.X.1418 Ramon de Sant Andreu, "dilecto familiari nostro", fue nombrado rector de Penàgui$1 a^{137}$. El 13 de ese mismo mes le concedieron además dos beneficios: uno en S. Lorenzo, bajo la invocación de S. Marcos, y otro en el monasterio de S. Vicente en la capilla de la Esperanza, y el documento lo cita como

\footnotetext{
129 Ibid. Caja 138/3, fols. 63 v. -64 r.

${ }^{130}$ Ihid. Caja 138/2, fols. 69 v. -70 r.

${ }^{131}$ Ibid. fol. 120 r.-v.

${ }^{132}$ Ibid. fols. $6 \mathrm{r} .-\mathrm{v}$.

${ }^{13.3}$ Ibid. fols. 20 r.-v.

${ }^{134}$ Ibid. fols. $21 \mathrm{r} .-\mathrm{v}$.

${ }^{135}$ Ibid. fol. $7 \mathrm{v}$.

${ }^{136}$ Ibid. fol. $101 \mathrm{v}$.

${ }^{137}$ Ibid. fols. 104 r. $-105 \mathrm{v}$.
} 
"presbitero, prefati domini episcopi Valencie familiari et continuo comensali"138. En un documento fechado el 18.VI.1421 aparece como testigo ${ }^{139}$.

12. Joan de Caldes (1421), en un documento fechado el 2.VI.1421 aparece como testigo Joan de Caldes, "clerico, domestico dicti domini episcopi" ${ }^{140}$.

13. Bertomeu Canet (1418-1421), el 18.IV.1418 le fue concedida la cura de almas por un año de la iglesia de Penáguila ${ }^{141}$, volviéndosela a conceder el 11.XII.1421, de la cual era beneficiado ${ }^{142}$. Una nota al margen dice "nihil quia de domo".

14. Guillem Ferri (1418-1421), el 20.I.1418 era clérigo en la iglesia de Sueca y fue sustituido por un año para celebrar por Pere Domínguez ${ }^{143}$. El 12.IX de ese año es también sustituido por un año en la cura de almas de Teulada por Lluís de Serraclara ${ }^{144}$. El 7.XI siguiente le fue concedido a Guillem Ferri, "clerico", permutar su beneficio de S. Miguel en Teulada con Pere de Muntagut, beneficiado en el de Todos los Santos de Gorga ${ }^{145}$. Una nota al margen del documento registrado dice "nihil quia de domo". El 28.VII.1421 le fue concedida a Guillem Ferri, "clerico, familiari nostro", la parroquia de Torres-Torres ${ }^{146}$.

15. Guillem Sala (1421), el 22.X.1421 el obispo concedió a Guillem Sala, "presbitero, in decretis bacallario, familiari nostro" el beneficio de $\mathrm{S}$. Blas en Albalat de la Ribera ${ }^{147}$.

16. Pere de Caldes (1425), en un documento fechado el 3.VIII. 1425 aparecen como testigos Pere de Caldes, "familiaris dicti domini episcopi Valencie" y

17. Bernat Pons $(1425)^{148}$.

\footnotetext{
${ }^{138}$ Ibid. Caja 138/3, fol. 47 v.

${ }^{139}$ Ibid. fol. $111 \mathrm{v}$.

${ }^{140}$ Ibid. fol. $39 \mathrm{v}$.

14llbid. Caja 138/2, fol. 49 v.

142Ibíd. Caja 138/3, fol. 119 v.

1+3 Ibid. Caja 138/2, fol. 12 r.

14Ibid. fol. $94 \mathrm{r}$.

145Ibicl. Caja 138/2, fols. 107 r.-v.

${ }^{1+6}$ Ibíd. Caja 138/3, fols. 69 v. -70 r.

${ }^{1+7}$ Ibid. folf. 106 v. -107 r.

${ }^{148}$ Ibid. Caja 139/1, fol. 96 v.
} 
18. Joan Periç (1425), el 16.II.1425 el obispo concedió una prórroga a Joan Periç, "presbitero, familiari nostro et beneficiato" para permutar uno de los dos beneficios que tiene en la catedral en el espacio de un año $0^{149}$.

\section{II.6. Parientes del obispo}

1. Anna de Rocafort (1408), el 12.I.1408 el obispo concedió a su "neboda nostra, filla de l'honorable En Pere de Roquafort, habitador del loch de Vinçà", 500 florines de oro de Aragón en ayuda de su matrimonio, que se le pagaron en cuatro pagas ${ }^{150}$.

2. Pere Çaroqua (1412), el 8.VI.1412 el obispo manda que se le paguen a Pere Çaroqua "donzell e habitador de la vila de Perpenyà, cosí nostre", 400 florines de oro de Aragón, que le asigna de sus rentas, en varias pagas ${ }^{151}$.

\section{Lugares de señorío de la mitra}

\section{III.1. Alcaide}

1. Esteve Valença (1412), con fecha de 2.IV.1412 el obispo concede a Esteve Valença, "dilectus procurator generalis noster... civis Valencie" la "alcaydia castri et loci predicti de Garg... cum salario quinquaginta librarum regalium Valencie de redditibus loci predicti annuatim recipiendarum pro vestri annuali salario"152.

\section{III.2. Hortelano}

1. Miquel Llop (1421), el 30.VII.1421, el obispo concedió de nuevo el cargo de hortelano de su huerto en el lugar del Villar a Miquel Llop, que ya lo había trabajado años antes, "adobat e millorat, plantat e arborat de molts bons arbres fruytals, com fos per lo senyor quondam cardenal de València quasi novellament costruijt e clos de parets com vench en vostre

\footnotetext{
1+19 Ibid. Caja 139/1, fol. 19 r.

${ }^{150}$ Ibid. Caja 137/2, fol. 7 r.

${ }^{151}$ Ibid. Caja 138/1, fol. 46 v.

152Ibid. fol. $91 \mathrm{v}$
} 
poder", y luego le fue quitado, y que después de él pase a su hijo Fran$\operatorname{cesc}^{153}$.

\author{
2. Francesc Llop.
}

\title{
RÉSUMÉ
}

Cette étude est une modeste contribution à l'histoire d'une cour médiévale épiscopale. Ce travail a pour bout de connaitre les personnes qui composaient la maison, la cour et la chancellerie de l'évêque du diocèse de Valencia, Hugo de Llupià (1408-1425), à travers les différents charges, offices, serviteurs et "familia". qui travaillèrent au service de l'administration épiscopale du diocèse et de l’évêque. Pour cela, nous avons utilisé cing registres du dit évêque conservés dans l'Archive Diocesain de Valence, qui correspondent aux années $1408,1412,1418,1421$ et 1425.

\section{SUMMARY}

This survey is our modest contribution to the history of a medieval episcopal court. Its objective is to know the people who were the components of the Household. Court and Chancellery of the Valencia diocese Bishop. Hugo de Llupia (1408-1425). through the different posts, trades. servants and "familia" members who performed their duties at the service of the diocese episcopal management as well as at the Bishop himself. To do this study we have made use of five records belonging to the mentioned Bishop which are kept in the Diocesan Archives of Valencia coresponding to the years 1408, 1412,1418,1421 and 1425 .

\footnotetext{
${ }^{153}$ Ibid. Caja 138/3, fol. 72 r.
} 